\title{
Oriented Keys to Overcome Problems in Small- Scale Gold Mining Sector in Tanzania: A Review
}

\author{
Olga Ibragimova, John Rugarabamu
}

University of Dodoma, Department of Mining and Mineral Processing Engineering, P.O.Box 259, Dodoma, Tanzania

\begin{abstract}
Tanzania's mineral potential can be harnessed to make a significant contribution to the national economy and the benefits may reach a wide spectrum of the population. Gold production has dominated Tanzanian industry for more than a century and stands at roughly 40 tonnes a year. Artisanal and small-scale mining (ASGM) is a feature of gold mining regions in Tanzania and plays a significant role as a direct source of employment in mining and in generating additional jobs in rural areas. Since the 1990s the Government has developed a legal and policy framework for integrating ASGM into a national mineral development strategy for economic growth and improvement of social well-being of the population. By now ASGM accounts for approximately $10 \%$ of Tanzanian gold production. However, the processing of gold ores can be highly problematic for ASGM, due to implication of low grade and more complex ores containing copper, arsenic and antimony minerals. It can cause lower gold recovery, increased reagent consumption and higher toxicity of the effluent. This paper identifies the main problems for ASGM, causes of failure and presents oriented keys to overcome mistakes, optimize the process, develop successful operations and manage the risks. At the same time the development of large-scale/small-scale relationships as an economic strategy is reviewed and compared with particular focus on the advantages and limitations in large-scale/small-scale partnerships.
\end{abstract}

Keywords: Small-Scale Mining, Refractory Gold Ores, Process Development, Large-Scale/Small-Scale Partnerships

\section{Introduction}

The Geological Survey of Tanzania shows that the country has 103 million tonnes of iron ore, 2.222 million tonnes of gold, 13.65 million tonnes of copper, 209 million tonnes of nickel, 50.9 million carats of diamonds, tanzanite (12.60 million carats) and 911 million tonnes of coal. Tanzania's mineral potential can be harnessed to make a significant contribution to the national economy and the benefits may reach a wide spectrum of the population [1]. Gold production has dominated Tanzanian industry for more than a century and stands at roughly 40 tonnes a year. Artisanal and smallscale gold mining (ASGM) is a feature of gold mining regions in Tanzania and plays a significant role as a direct source of employment in mining and in generating additional jobs in rural areas. ASGM activities involve gold production from hard rocks and alluvial deposits located in multiple regions of the country, especially in the area near Lake Victoria in North Tanzania [2]. Figure 1 shows the location of ASGM activities in Tanzania.

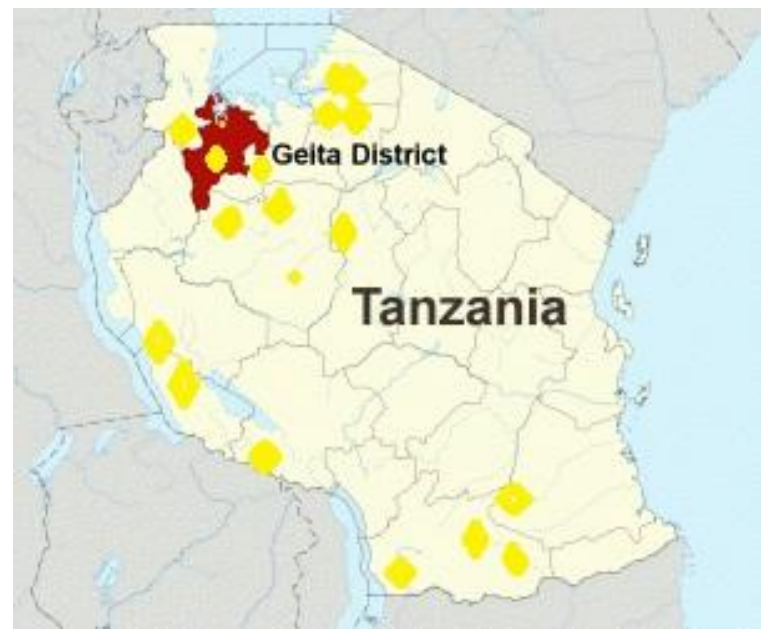

Figure 1: Map of ASGM mining in Tanzania
Generally speaking ASGM is characterized as the sector exploiting marginal or small deposits, lacks capital, is labour intensive, has poor access to markets and support services, and has low standards of health and safety [3]. In regards to the number of ASGM there are 20 million small-scale miners over the world. In view of the occurrence of ASGM it is evident that they can be found in the most distanced regions and areas in the world and involve the poorest people [4].

Opinion in recent years, influenced partly by some governments simply neglecting small-scale miners, has tended forwards making the ASGM the potential for environmental damage and conflicts because it falls outside the regular frameworks. On the other hand there is a tendency over the past 15 years to recognize ASGM as a legitimate route out of poverty. Tanzania's ASGM sector began to grow in the $1980 \mathrm{~s}$. The global increase in gold price has become a significant factor to attract people into small-scale mining. The downturn in the performance of other productive industries, poor markets for agriculture and other factors have been associated with the increase in the number of people working in ASGM in the 1980s and 1990s. By now the population of artisanal and small-scale miners in Tanzania is estimated to be 500,000 -1,500,000 [5].

Since 1990s the Government of Tanzania has developed a legal and policy framework for integrating ASGM into a national mineral development strategy for economic growth and improvement of social well-being of the population. According to statistical data by now ASGM accounts for approximately $10 \%$ of Tanzanian gold production [6]. However, the processing of gold ores can be highly problematic for ASGM, due to implication of low grade and more complex ores containing copper, arsenic and antimony minerals. It can cause lower gold recovery, increased reagent consumption and higher toxicity of the effluent.

\section{Volume 5 Issue 8, August 2016}




\section{International Journal of Science and Research (IJSR) \\ ISSN (Online): 2319-7064}

Index Copernicus Value (2013): 6.14 | Impact Factor (2015): 6.391

\section{Research Objectives}

This paper shows the key problems affecting the ASGM sector and exploits the existing experience for improvement and development. Problem framing, engagement of legal activity, important contribution from the Government and large-scale companies are also under investigation. Large companies' engagement strategies for ASGM are critically reviewed and compared with particular focus on the advantages and limitations of large-scale/small-scale partnerships.

\section{Methods}

The study used interviews and questionnaires conducted to involve Mineral Processing Engineering students of the University of Dodoma (Tanzania) in assistance to evaluate the problems in the ASGM sector.

\section{Results and Discussion}

\subsection{Problem Description}

We assume that ASG miners lack the most significant technical, social, economic and other infrastructures not allowing them to take advantages of technical progress and get out of poverty. The main problems and causes of failure should be indicated to avoid mistakes in near future. Table 1 shows the various causes and effects on the situation in ASGM sector.

Table 1: Cause and effect

\begin{tabular}{|c|c|}
\hline Cause & Effect \\
\hline Poor geological prospecting & Low efficiency of excavating \\
\hline Exploiting the same mining sites & $\begin{array}{c}\text { Competition leading to increase } \\
\text { in poverty }\end{array}$ \\
\hline Depletion of mineral resources & Low efficiency \\
\hline Low education & Unskilled labour \\
\hline $\begin{array}{c}\text { Lack of appropriate technologies } \\
\text { Lack of appropriate equipment } \\
\text { and tools }\end{array}$ & $\begin{array}{c}\text { Low productivity and high level } \\
\text { of accidents }\end{array}$ \\
\hline Lack of legal framework & Low economic development \\
\hline Lack of financial assistance & Low investments \\
\hline $\begin{array}{c}\text { Poor safety and working } \\
\text { conditions }\end{array}$ & $\begin{array}{c}\text { Health degradation and high } \\
\text { level of diseases }\end{array}$ \\
\hline $\begin{array}{c}\text { Application of cheap but harmful } \\
\text { chemicals }\end{array}$ & Environmental damage \\
\hline
\end{tabular}

According to Table 1 the reported information indicates strong correlation between cause and effect of low productivity in the ASGM sector. Consequently, the information generated from interviews in Table 1 revealed that the majority of respondents agreed with the factors that were provided.

\subsubsection{Poor Geological Prospecting and Exploiting the Same Mining Sites}

Gold from alluvial deposits can be assessed easily and does not need the complicated preparation stage for ASGM. They totally neglect the prospecting stage and have no reserve estimation. Very often they are poorly organized and lacking in work preparation before production. As a result ASG miners are working in tiny mining sites with low efficiency. According to poor organization the ASG miners exploit the same mining sites which create great competition between them. This competition leads to an even greater level of poverty. As a consequence they have to shift from one site to another, working on both registered and unregistered land.

\subsubsection{Depletion of Mineral Resources}

Nowadays this is the tendency to which leads to the exploitation of refractory gold ores. The majority of these ores are complex and many of them contain significant amounts of arsenic, bismuth, antimony and copper minerals. The presence of copper, arsenic and antimony cause a number of problems, including lower gold recoveries, increased cyanide consumption and increased toxicity of the effluent. The selection of options to treat a specific ore is significantly impacted by factors such as mineralogy, precious metal grades and deportment, gold to sulfur ratios and hazardous impurities. Over the years, a variety of processes has been developed or proposed to recover valuable metals including acidification based technologies such as AVR and SART, direct electrowinning, activated carbon, ion exchange resins, solvent extraction, polychelating polymers, and membrane technologies. Unfortunately, most of these technologies can only be applied by large-scale mining companies, leaving ASGM out of progress. It appears that ASG miners need to move to far distances searching for large and rich ore bodies or accept the situation and treat the existing resources. As a result the efficiency of mining and mineral processing operations to extract gold from refractory ores without appropriate modern technology is very low.

\subsubsection{Low Education and Lack of Appropriate Technologies, Equipment and Tools}

The majority of small scale miners possesses minor technical knowledge of mining and mineral processing, which results in unskilled labour with low efficiency. Operations range from semi-mechanized and mechanized mining to the extraction of minerals using simple technologies and no mechanization. In fact the lack of appropriate and innovative technologies leads to wastage of minerals due to poor gold recovery. Another problem is gold extraction by amalgamation, the ancient method of gold recovery, which releases large amounts of mercury into the environment as metallic mercury, which is later transformed to metholated mercury, a powerful neurotoxin that is readily absorbed by biological tissue and is toxic to humans and wildlife alike[7],[8].The high health risk of mercury is well known over the world but in the remote and rural areas in Tanzania small-scale miners lack this information. It was established that by now more than 500,000 ASG miners in Tanzania still extract gold using mercury. Equipment used for mineral extraction by ASGM can be differentiated between those whose operations are purely manual and those that have introduced some mechanical equipment. In most manual operations, the equipment, most of which is fabricated at the mining site, are very rudimentary [9]. For excavation and mineral processing operations they are using picks, shovels, pans and hand hammers. 


\section{International Journal of Science and Research (IJSR) \\ ISSN (Online): 2319-7064}

Index Copernicus Value (2013): 6.14 | Impact Factor (2015): 6.391

4.1.4. Lack of Legal Framework and Financial Assistance We must take into consideration the informal mining operations involving ASGM. A legal framework has significant value for ASGM. Unlicensed miners are vulnerable to losing official support which can lead to lack the protection and opportunities provided by the Government. It appears that small-scale miners have a fear of being recognized officially due to various reasons. Firstly, there is the small scale of the operations. Then they are not familiar with the market fluctuation showing the instability of it. Small-scale miners do not expect to continue their activity for many years. The law of "gut feeling" goes into play giving rise to the reaction of minimizing the legal activity. Most of them do not expect assistance but rather increase in the load of regulations restricting the activity.

It has been recognized that $80 \%$ of small-scale mining activity in the region is informal [9]. This sector is flexible and difficult to control. ASG miners often rely on informal financiers, who often control the sale of this gold in an organized and sophisticated way. It is an activity that has been done in many communities for centuries. However, given the low levels of formal employment where largescale operations exist, it has taken on an increasing level of risk where communities encroach on mining lease areas and illegally enter company mining areas.

\subsubsection{Application of Cheap but Harmful Chemicals}

In environmental aspects ASGM shows poor handling of chemicals during mineral processing operations. Very often small-scale mining operations cause erosion, deforestation, water pollution and finally, degradation of the environment. It is known that traditionally gold is recovered through crushing, grinding, gravity separation and amalgamation. Because of its simplicity and cheapness, it is not surprising that mercury amalgamation should be an ideal method to extract gold for ASGM. However, ASGM also poses significant environmental and health risks arising from mercury application. During this process, mercury is introduced into the environment through disposal of process water and tailings, while open-air firing of the gold/mercury amalgam releases mercury vapour to the atmosphere. It has been established that annually more than 1000 tons of mercury are released into soil, water and air. Mercury emissions from informal gold-mining operations represent a serious environmental problem in Tanzania [10].

\subsection{Oriented Keys to Overcome the Past Mistakes}

\subsubsection{Legalization}

Often the process of legalization is complicated and bureaucratic, creating obstacles for miners. It is obvious that the way to attract the small-scale miner to this process is improvement in the legalization procedure to make it simple and clear for people. There is every indication that the Tanzanian Government continues to manage this sector to create suitable conditions to turn to the formal and legal sector to use country resources efficiently.

\subsubsection{Training Programs}

Mining, Material and Metallurgical Education in Tanzania has experienced constant and considerable change over the last ten years. Dar-es-Salaam Institute of Technology and the University of Dodoma became leading providers of Engineering education within Tanzania. To create a place where knowledge and skills in Mining, Material and Metallurgical Education will be transferred from one generation to another and produce sustainable economic development of the country, the university becomes a center of training innovative talents, scientific research and consultancy services in the areas of Earth Sciences and Engineering [11]. It has been established that ASG miners lack of appropriate technical knowledge and best practice approach for mining operations. Therefore the Institute of Technology came with the initiative to conduct and promote short-term courses for ASGM [12]. Also the project will serve as a platform of dialogue for enhanced collaboration between small-scale and large-scale mining. The authors believe that it will be the strengthening effect on ASG miners' capacity to become more productive. In addition the authors consider that creative dialogue between ASGM and the Government is the universal approach to formulate new meaning and help miners to adhere to the new knowledge. In 2006, the Tanzanian Government partnered with the United Nations Industrial Development Organization (UNIDO) to develop a "Manual for Training Artisanal Miners" and create training programs in ASGM communities in Geita District [13]. By using relevant teaching methods, the professional competent supervisors and consultants can stimulate small-scale miners for selfimprovement.

\subsubsection{Innovative Technologies}

Some ASGM communities continue to practice the same method of gold extraction developed by their forefathers, whereas other groups are creative and try to improve working techniques to increase gold recovery rates. The innovative method was suggested by group of researchers to replace harmful amalgamation for gold recovery [14]. According to the reported results the borax method is cheaper than amalgamation and gives a higher recovery of gold. This method is successfully implicated in the ASGM sector in the Philippines. Some studies have been done in Tanzania. It gives the hope of convincing millions of miners around the world to use borax for gold extraction, significantly reducing global mercury pollution. Unfortunately, it should be noted that the borax method is not appropriate for all types of gold ores. Ores which are rich in sulfur or contain fine gold grains, can show some difficulties in successful extraction. It is evident that appropriate mineralogical testing should be done.

\subsubsection{Financial Support}

The Government emphasizes the improvement of smallscale miners' access to credit and small-scale mining loans by formal financial institutions. It has been proposed to formulate affordable credit schemes to the miners as well as establishment of mobile banking systems, to use third-party guarantees to enable other institutions to assist miners to get loans, to create mineral property markets to enable discoverers to sell their properties to developers at competitive prices. It is obvious that this strategy can improve small-scale miners' access to finance.

\section{Volume 5 Issue 8, August 2016}




\section{International Journal of Science and Research (IJSR) \\ ISSN (Online): 2319-7064}

Index Copernicus Value (2013): 6.14 | Impact Factor (2015): 6.391 4.3. Small-Scale/ Large-Scale Mining: Conflict of
Interests or Partnership

\subsubsection{History of Relationships}

Tanzania is one of the main countries for small-scale mining activity. However, compared with Tanzania's large-scale mining, the ASGM sector is smaller in its output but larger by labour absorption. It is a safe assumption that more people are involved in the small-scale rather than in the large-scale mining industry. Moreover, it also has had exceptional increase within ten years, outperforming the large-scale mining by at least $30 \%$ in this respect. Although the Tanzanian Government recognizes small-scale mining as an important contributor to national economy, very often the ASGM sector is taken into account as a serious and potential strategic means to pressure foreign companies to accept more stringent conditions for mineral exploitation [15]. It is likely that in some specific areas a growing ASGM can provide the establishment and development of local mining as well as play the role as a temporally limited alternative to large-scale mining operations.

Since the last century, the relationship between small-scale and large -scale mining remains a troublesome question for the researchers, showing conflicts as well as a chance for cooperation. From the German colonial period, gold discoveries had been made in Geita, Kahama and Sekenke in the Lake Victoria region in the 1890s. At this time, small-scale gold mining was carried out on alluvial rich deposits. The ASGM sector was negligible due to lack of native artisanal activities. Although the first small-scale gold mine was opened at Sekenke in 1909, the activities of large companies was started with development of gold mines in Musoma and Geita. Establishment of the Geological Survey Department and enactment of mining laws in 1920s by the British administration led to an increase in prospecting involvement of medium and large scale companies. Before the Second World War gold production was in progress in Tanganyika with record levels attained in 1940 to the value of $£ 1.2$ Million. As a consequence artisanal and ASGM had often adhered to virgin exploration sites and larger-scale mines in the Lake Victoria region and Southern Lupa Goldfields, to take advantage of better access to deposits [9]

\subsubsection{Present Co-existence}

By now in many cases the relationship between small scale and large mining companies has been troubled by mutual distrust and indignation from both sides giving strong negative feelings. There is a number of reasons which cause these difficulties in understanding. The most important reason is the competition for the same mineral resources. Many deposits now extracted by large-scale mining companies were initially discovered by artisanal miners. These difficulties arise in gold-rich areas when the large scale mining companies have got the license for mining and processing. In addition ASGM are usually allocated tiny mining sites that make it difficult to operate without interfering with each other. Nevertheless there are some important factors indicating the prospective successful cooperation between small-scale/ large scale mining sectors in Tanzania. As a country Tanzania is politically stable and safe. The government focuses on legal and regular frameworks. Finally, the geology of the country assures peaceful co-existence of both small- and large-scale mining companies for further mineral resource discoveries.

\subsubsection{Future Partnership}

Large-scale mining companies in Tanzania recognize positive contributions of the ASGM sector to the national economy such as employment of people from the rural areas, discovery of minerals and economical mineral production located in remote areas, and profit generation. During recent years large companies have started to establish engagement strategies for ASGM. They understood that construction of trust and strengthening of relationships is the key to avoid conflicts between smallscale/large-scale mining. In 2014 a pilot project aimed to improve conditions and livelihoods for small-scale miners, decrease environmental degradation and facilitate the peaceful co-existence between LSM and ASM, started in Geita region. It is the collaborate efforts of the Government of Tanzania, the World Bank group, large-scale mining companies Anglo Gold Ashanti and African Barrick Gold and ASGM [16]. The companies provided for investment across health, water, education and alternative livelihoods within the seven villages surrounding the mine and has significantly improved the relationship with the community [17]. It is obvious that now large-scale mining companies recognize that the future is a dialogue, a collaboration between ASGM and large business. However, there are some steps which should be done for further successful coexistence of these two sectors.

1) Providing the general information about exploration and closure of the mine to minimize negative effect of LSM activities on ASGM

2) Training of ASGM to improve their skills in mining methods, geology, mine pegging, environmental management, health and safety, business planning and management

3) Promoting change in the mining and refining methods to reduce environmental impacts and improve gold recovery

4) Strategic planning for contribution to the development of the ASGM communities

5) Providing financial assistance for technical improvement

6) Involving local people in construction and maintenance activities

7) Managing the security in accordance with the COP provision on Security which references the Voluntary Principles on Security and Human Rights.

\section{Future Scope and Implications of the Study}

The knowledge generated in these studies is extremely helpful in further understanding the perspective of the coexistence of small-scale and large-scale mining as well as in the designing of new legal frameworks for ASGM.

\section{Conclusions}

Artisanal and small-scale mining (ASGM) is a feature of gold mining regions in Tanzania and plays a significant role as a direct source of employment in mining and in generating

\section{Volume 5 Issue 8, August 2016}




\section{International Journal of Science and Research (IJSR) \\ ISSN (Online): 2319-7064}

Index Copernicus Value (2013): 6.14 | Impact Factor (2015): 6.391

additional jobs in rural areas. However, the processing of gold ores can be highly problematic for ASGM, due to implication of low grade and more complex ores containing copper, arsenic and antimony minerals. Which can cause lower gold recovery, increased reagent consumption and higher toxicity of the effluent. The main problems and causes of failure such as low education, poor geological prospecting, exploiting the same mining sites, depletion of mineral resources, lack of appropriate equipment, technologies, legal framework and financial assistance, poor safely and working conditions have been indicated. It has been established that the oriented keys to overcome mistakes, optimize the process, develop successful operations and manage the risks are legalization, training programs, innovative technologies, collaboration and financial support from large-scale mining companies and the government. While it is early to draw conclusions regarding the impact of large companies engagement strategies for ASGM to future success of coexistence and collaboration between small-scale and largescale mining, it appears that recent efforts have been the important steps in developing partnerships.

\section{Acknowledgments}

The authors would like to thank the staff, management and Mineral Processing Engineering students of the University of Dodoma for their collaboration.

\section{References}

[1] The mineral policy of Tanzania, Ministry of Energy and Minerals, October, 32,1997.

[2] Ombeni J.M. Potential of artisanal and Small-scale gold mines for economic development in Tanzania: a review. Journal of Geology and Mining Research. V7(2), pp11$18,2015$.

[3] MMSD. Breaking New Ground: Mining, Minerals and Sustainable Development, IIED, London.Available at http://pubs.iied.org/pdfs/ G00905.pdf, 2002

[4] Buxton A. Responding to the challenge of artisanal and small-scale mining. How can knowledge networks help? IIED, London, 2013.

[5] Carstens .J, Cattett N., Lintzer M., Priester M., Hetschel T. Implementing Transparency in the Artisanal and Small Scale Mining Sector. Project Consult with Resources Consulting Services, 2009.

[6] UNEP. Analysis of formalization approaches in the artisanal and small-scale gold mining sector based on experiences in Ecuador, Mongolia, Peru, Tanzania and Uganda/UN Environmental Program, 2013

[7] Jønsson J.B., Appel P.W.U., Chibunda R.T., A matter of approach: The retort's potential to reduce mercury consumption within small-scale gold mining settlements in Tanzania. Journal of Cleaner Production 17(1):pp.7786, 2009.

[8] Kinabo C.Mercury, Health and Environment. A paper on an International Workshop on the Environmental Management of Artisanal and Small-scale Mining Activities, September 2000, Mwanza, 2000.

[9] Mwaipopo R., Mutagwaba W., Nyanga D., \& Fisher E., Increasing the Contribution of Artisanal and Small-Scale
Mining to Poverty Reduction in Tanzania. London, UK: Department for International Development, 2004.

[10]Dreschler B. Small-scale Mining and Sustainable Development within the SADC Region. MMSD.№ 84, pp.63-90, 2001.

[11] Ibragimova O. Creative Education as an Engine of Innovative Talents Cultivation. International Journal of Science and Research, Vol.3, Issue 10, pp 877-881, 2014 .

[12] Institutional Profile and Terms of reference.ISTEP04.Dar-es-Salaam Institute of Technology,p 10, 2014

[13] Veiga M.M.; Metcalf S., Baker R., Klein B.; Davis G., Bamber A., Siegel S.; Singho P., Manual for Training Artisanal and Small-Scale Gold Miners. United Nations Industrial Development Organization: Vienna, Austria. Retrieved

from http://www.globalmercuryproject.org/documents/non co untry $\% 20$ specific/training $\% 20$ manual $\% 20$ for $\% 20$ miners \%20Marcello\%2015.pdf,2006.

[14] Appel P., Na-Oy L., The Borax Method of Gold Extraction for Small-Scale Miners. Blacksmith Institute Journal of Health \& Pollution Vol. 2, No. 3, pp 5-10, 2012.

[15]Bryceson D., Jonsson S., Tanzanian Artisanal Gold Mining: Present and Future. Geographical and Earth Sciences. University of Glasgow/London: BritishTanzania Society Seminar (SOAS), 2012.

[16] World Bank. Small scale mining. Available at http://go.worldbank.org/4K0MT244R0, 2013.

[17] Acacia Mining PLC Responsible Mining report 4. Available http://www.acaciamining.com/ /media/Files/A/Acacia/re ports/2015/2014-sustainability-eport.pdf,2014

\section{Author Profile}

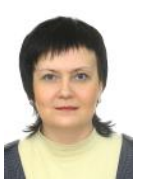

Olga Ibragimova received the MS degree in Mineral Processing Engineering from the Moscow Institute of Steel and Alloys, Russia in 1986. During 1986-1994 she stayed in Ore Dressing Laboratory, Institute of Chemistry,Tajik Academy of Science to study the phenomenon of the effect of combination of sulfur-containing collectors on non-ferrous ores flotation using spectroscopic methods. Then she has been an associate professor at the Samara State Technical University, Russia, over the past 15 years. Presently, she is teaching at the University of Dodoma, Tanzania. Current research interests include Computer Modeling of Chemical Compounds and Processes.

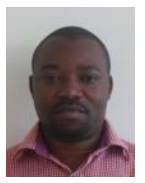

John Rugarabamu received the MSc-degree in Environmental Technology and Management from Ardhi University in 2014. Presently, he is a Head of Mining and Mineral Processing Engineering Department, University of Dodoma, Tanzania. Current research interests are devoted to development of capacity in research that integrates environmental management skills with mining professional so as to solve the fast growing mining related environmental issues in the world especially those causing the Climate Change. 